\title{
LEITURA E ESCRITA: EXPERIÊNCIAS TEÓRICO-METODOLÓGICAS EM SALA DE AULA
}

\author{
Raimundo Nonato de Oliveira FALABELO ${ }^{1}$ \\ Campus Universitário de Cametá/UFPA \\ falabelo@ufpa.br \\ Dionéia Sanches LEÃO² \\ Prefeitura Municipal de Cametá \\ dioneiasanches@hotmail.com
}

Resumo: A finalidade deste artigo é apresentarum recorte discursivo sobre os resultados de uma pesquisa realizada em uma turma de $1^{a}$ série do ensino fundamental. Desenvolvemos atividades didáticas e culturais que viessem permitir a troca de experiência, conhecimentos e saberes, com o propósito de possibilitar a interação entre crianças que vivem em uma realidade de violência e exclusão dos bens materiais e simbólicos. À medida que as ações foram acontecendo, observamos graduais mudanças na configuração afetiva na sala de aula, provocando alterações e novos modos de relação das crianças com os conhecimentos a elas disponibilizados. Verificamos que o conhecimento mobilizava as crianças, revelando os laços de afetividade que iam sendo produzidos nas relações de aprendizagem. Ao compreender-se aprendendo e se apropriando, as crianças modificaram seus comportamentos e atitudes em relação a si mesmas, à professora, aos conhecimentos trabalhados e à escola.

Palavras-chave: Leitura. Escrita. Ensino-aprendizagem. Afetividade.

Abstract: This articles intends to present a discursive view about the results of a research made with a first grade group of elementary school. Didactical and Cultural activities were developed in order to permit the exchange of experience, knowledge and wisdoms and enable interaction between the children who live in a reality of violence and exclusion of symbolic and corporeal property. According actions were happening, gradual changes were observed in the affective configuration in the classroom, provoking alterations and new ways of relationship of the children towards knowledge provided to them. It was observed that knowledge motivated

\footnotetext{
${ }^{1}$ Professor Adjunto IV, Faculdade de Educação, Campus de Cametá/Universidade Federal do Pará. Cametá/PA.

${ }^{2}$ Pedagoga/Professora das Séries Iniciais/Prefeitura Municipal de Cametá. Bolsista de Iniciação Científica. Programa de Apoio ao Recém-Doutor/UFPA/CAPES.
}

\section{5}


children, making them see the links of affectionateness that are being produced in the relationships of learning. Getting aware of the learning, absorbing knowledge were actions that modified behaviors and attitudes of the children towards themselves, the teacher and their knowledge worked at school.

Keywords: Reading. Writing. Teaching-Learning. Affectionateness.

\section{Introdução}

O dia-a-dia se acha semeado de maravilhas, escuma tão brilhante [...] como a dos escritores ou dos artistas. Sem nome próprio, todas as espécies de linguagens dão lugar a essas festas efêmeras que surgem, desaparecem e tornam a surgir (M. Certeau).

O atuar em uma área como a educação, povoada por diferentes formas discursivas e intertextualidades, muitas das quais prescritivas, normativas, adrede organizadas em autoritários manuais de pedagogia, impõe-nos questões de como instaurar outras possibilidades de intercambiamento de saberes e experiências entre o mundo do trabalho (a sala de aula) e a pesquisa acadêmica.

Neste recorte discursivo, em forma de narrativa, procuramos dar a ver que, no exercício de fazer docência, também se pode fazer ciência, captando e apreendendo, na ordinária rotina da sala de aula, alguns eventos singulares, fortuitos, que se despregam do comum, fazendo, assim, emergir alguma originalidade, algo que se poderia caracterizar como produção de conhecimento.

Ao mesmo tempo, em sua intencionalidade e planejamento (teoria e metodologia), forjamos situações didático-pedagógicas e culturais que desestabilizassem a rotina da sala de aula, o lugar comum do dia a dia, quando assim o observamos, para que pudéssemos apreender possíveis fios de mudança e transformação nas atitudes de alunos e professor/a. $\mathrm{Ou}$ seja, procuramos instaurar situações experimentais, quebrando o mecânico ato de repetir-se das aulas de cópia e ditado, ditado e cópia, situação sobejamente denunciada em pesquisas sobre o cotidiano escolar.

A narrativa encontra-se assim estruturada: Introdução; um tópico tratando brevemente da questão da relação afetividade e conhecimento nas relações de ensino, e outro sobre a questão da leitura e escrita, a partir 
dos trabalhos de Vygotsky, elaborador da abordagem teórica históricocultural do desenvolvimento humano; em seguida, apresentamos o percurso, resultados e conclusões sobre os eventos didáticos, pedagógicos e culturais, como acontecimentos de pesquisa, realizados com crianças de uma $1^{\mathrm{a}}$ série do ensino fundamental.

\section{A Perspectiva Histórico-Cultural do Desenvolvimento Humano}

A perspectiva histórico-cultural do desenvolvimento humano desenvolvida por Vygotsky e colaboradores defende a tese de que o ser humano adquire seus modos de pensar, sentir e agir no contexto das relações e das práticas sociais, sendo assim, suas principais funções psíquicas, isto é, seu funcionamento psicológico é constituído nas relações com os outros, mediados pelos conhecimentos-cultura e pela linguagem.

Se para Vygotsky (1998) nos constituímos nas relações intersubjetivas, mediadas pela cultura e pela linguagem, então, quanto mais ricas e mais diversificadas forem as práticas sociais de aprendizagem, maiores possibilidades terão os sujeitos de se desenvolverem, de ampliarem e alargarem suas funções psicológicas, sua formação humana. É a relação, a inserção na cultura (rica e diversificada) que promove o desenvolvimento daquilo que nos é especificamente humano. Podemos dizer que, para Vygotsky, os modos humanos são históricos e culturais, próprios de determinado contexto sociocultural.

Assim, as formas como pensamos, agimos e nos comportamentos, sentimos, amamos e odiamos constituem socialmente a nossa vida cognitiva e afetiva. $\mathrm{O}$ conteúdo do psiquismo não está no interior do indivíduo, mas no exterior (no social) e é constituído pelos diversos e diferentes processos de aprendizagem que o indivíduo, na sua interação com o(s) outro/ outros, mediado pela linguagem, vai se apropriando e internalizando os saberes/cultura/conhecimentos valorizados pelo grupo social (FALABELO, 2005).

A criança, então, diz Vygotsky (1998), reconstrói internamente os modos culturais de ação e pensamento/sentimentos que foram compartilhados com ela nas relações intersubjetivas com os adultos. O processo de internalização/apropriação, primeiramente, de atividade 
interpessoal transforma-se em atividade intrapessoal, constituindo o funcionamento interno do indivíduo. Isso significa considerar que o processo de desenvolvimento vai do social para o individual, de modo que as nossas formas de pensar, perceber, agir, sentir etc. são resultados da apropriação dos modos culturais de ação e pensamento/sentimentos que vêm se desenvolvendo e se transformando no percurso do desenvolvimento histórico da humanidade.

Então, nos baseamos nesse referencial teórico, instauramos situações didático-pedagógicas e culturais e, ao mesmo tempo, investigamos como professores e crianças vivem e compartilham as práticas de leitura e escrita em sala de aula, buscando evidenciar: a) a questão da mediação afetiva na apropriação dos conhecimentos; b) as possíveis transformações e mudanças de atitudes dessas crianças em relação aos conhecimentos a elas disponibilizados; c) em relação à professora, os indícios de ressignificação de seu fazer docente.

Esperamos, ao articular teoria e prática, ampliar a compreensão do papel fundamental da afetividade na apropriação dos conteúdos programáticos em sala de aula. O objetivo é aprofundarmo-nos o conhecimento sobre a inter-relação afetividade - conhecimento/cognição nas relações de ensino, superando ou, digamos, relativizando a visão racionalista do homem presente no paradigma da modernidade e ainda muito predominante no campo pedagógico.

Ressalte-se que a afetividade pesquisada é aquela que se dá nas relações com os conhecimentos; ou seja, a apropriação do conhecimento (o aprendizado incorporado) afeta o sujeito, ampliando e sustentando as relações pedagógicas. Assim, o estudo procura partir do pressuposto de que a afetividade não é apenas algo inerente ao professor, mas mostra-se na relação intersubjetiva, mediada pelo conhecimento em circulação e em elaboração, de forma que a afetividade está no professor, no aluno e nos próprios conhecimentos (FALABELO, 2005).

\section{Leitura e Escrita: Um Olhar Histórico-Cultural}

Para Vygotsky (1998), a leitura e a escrita não são elementos inatos à criança. Sua aquisição depende das práticas sociais e culturais nas quais a mesma está inserida. A compreensão da leitura e da escrita não se dá 
de forma isolada, não é algo trazido em seus aspectos biológicos, mas construído em suas relações sociais, em sua relação com o(s) outro/ outros e com os conhecimentos. É, pois, na troca de experiências que se possibilita a aprendizagem e a aquisição da escrita, o acesso ao mundo simbólico.

O papel da escola é dar a essas crianças, em um contexto sistemático, possibilidades para que elas possam se desenvolver, pois devemos olhar as crianças não apenas em suas dificuldades, mas:

"o que temos que buscar são as forças positivas do defeito, dirigindo-nos para alcançar o que é socialmente valorizado, construindo assim a autoestima perdida ou não estabelecida" (PADILHA, 1997, p. 33).

O que parece acontecer no contexto escolar é que só se consegue enxergar as dificuldades que as crianças apresentam no processo de aquisição da leitura e da escrita, sem se perguntar como ocorreu esse processo antes de sua entrada na escola, em que contexto sociocultural estas crianças se encontravam e se encontram inseridas. É num mundo de leitores ou num mundo em que a leitura e a escrita são pouco valorizadas?

Em relação a essa situação, Vygotsky (1998, p. 130) chama a atenção para o fato de que "o aprendizado volta-se para as deficiências da criança, ao invés de se voltar para os pontos fortes...". Ainda para Vigotski, a escrita tem grande significado para as crianças, despertando nelas necessidades próprias, pelo fato de se juntar a uma tarefa necessária e importante para a vida e, assim, desenvolver-se como uma forma nova e complexa de linguagem.

Vygotsky (1997) faz ácida crítica à maneira formal e mecânica a respeito do ensino da escrita. O ensino tem de ser organizado de forma que a leitura e a escrita se tornem necessárias às crianças. Se for usado apenas para escrever congratulações oficiais para membros da diretoria escolar ou para qualquer pessoa que o professor julgar interessante (e sugerir claramente para as crianças), então o exercício da escrita passará a ser puramente mecânico, e logo poderá entediar as crianças, pois suas atividades não se expressarão em sua escrita e suas personalidades não desabrocharão. A leitura e a escrita devem ser algo de que a criança necessite.

Em seu cotidiano, por estar inserida em uma sociedade letrada e hipersemiotizada, a criança sente a necessidade da leitura e da escrita para

\section{9}


tentar realizar algo que a ela é necessário, pois busca o aprendizado de forma a se realizar como ser humano e se constituir como indivíduo.

A criança vai à escola com a expectativa de conseguir esse aprendizado, mas, infelizmente, depara-se com algo totalmente diferente da sua realidade, pois a leitura e a escrita são apresentadas de forma mecânica, vistas como uma obrigação e não como desejo de adquiri-la, sem significado para ela, o que acaba gerando o desinteresse, o fracasso e a evasão escolar.

Essa é a grande crítica que Vygotsky (1998) faz ao ensino da leitura e da escrita: um processo estéril e desvinculado das necessidades maiores das crianças e do desenvolvimento de sua consciência.

A leitura e a escrita são elaboradas pela criança nas suas relações sociais, necessitando sempre do outro como mediador nesse processo. A elaboração ativa da escrita depende principalmente das possibilidades que as crianças têm ou não de utilizá-la e compartilhá-la em suas interações: tudo depende do contexto sociocultural ao qual cada indivíduo está inserido.

Vygotsky não considera que as relações da criança com a escrita sejam estritamente cognitivas, ou seja, não é apenas um objeto de conhecimento, mas também uma forma cultural de ação no mundo; o conhecimento da escrita é utilizado pelo indivíduo para agir na sociedade. Segundo Smolka (1998, p. 63), baseada em Vygotsky:

A palavra materializada sobre o papel não é um fim em si mesmo. Ela cria relações entre os indivíduos: a criança aprende a ouvir, a entender o outro pela leitura, aprende a falar, a dizer o que quer pela escrita. Mas esse aprender significa fazer, usar, praticar, conhecer. Enquanto escreve, a criança aprende a escrever e aprende sobre a escrita.

A leitura e a escrita vão além de mero conhecimento formal, sua aquisição possibilita a compreensão acerca dos fatos, das pessoas, do mundo, mas esse aprender precisa ser usado, praticado para poder ganhar sentido, valor, significado. Não se pode ensinar a escrita para a criança como algo sem importância, desprovido de significado, como uma maneira de copiar palavras, formar frases apenas, sem mostrar a sua importância e indispensavelmente sem fazer ligação com a realidade. A leitura/escrita 
precisa ser ensinada de forma a fazer parte do funcionamento mental e social da criança.

A leitura, em nenhum momento, pode ser vista pela criança como algo desnecessário, sem importância, uma obrigação, uma tarefa técnica realizada sobre pressão, mas sim como algo necessário, como arte e magia, que lhe possibilita nomear o mundo; como descobrimento, que abrirá caminhos para se alcançar objetivos, atingir metas, de forma dinâmica, livre, feita de acordo com suas necessidades, ampliando a dimensão sígnica daquilo que chega a ela, ampliando suas competências e habilidades cognitivas, afetivas etc.

A escrita é o culminar de processos elaborados de representação da realidade, que passa por diferentes manifestações em sua construção (pensamento, fala oral, fala interior) até chegar à sua forma mais abstrata e convencional. $\mathrm{Na}$ fala, a criança mal tem consciência dos sons que emite e está bastante inconsciente das operações mentais que executa. $\mathrm{Na}$ escrita, ela tem que tomar conhecimento da estrutura sonora de cada palavra, dissecá-la e reproduzi-la em símbolos alfabéticos que devem ser estudados e memorizados, pois, como diz Vigotski (1993, p. 85): “da mesma forma deliberada tem que por as palavras em certa seqüência, para que possa formar uma frase".

$\mathrm{Na}$ perspectiva histórico-cultural, compreender a relação das crianças com a leitura e a escrita representa a compreensão do contexto social e histórico nos quais essas crianças estão inseridas. Compreender como se dá a leitura e a escrita na sala de aula significa compreender as relações sociais que caracterizam esse contexto e como elas contribuem ou não para a formação de leitores e escritores. É necessário considerarmos os alunos reais, que habitam as salas de aula da atualidade, buscando compreender suas necessidades reais e suas capacidades emergentes.

\section{Breve olhar da Escola sobre as crianças}

Essas crianças, não encontrando outros caminhos, outras saídas, acabam se envolvendo com o mundo do crime, da prostituição, do uso das drogas. Na escola, elas experimentam sucessivos fracassos, repetência e seu lado mais perverso, a discriminação. Professores e membros do corpo administrativo da Escola viam-nas como pessoas perigosas, 
marginais, por pertencerem à classe baixa da sociedade e viverem nas periferias. Criticavam seus comportamentos, rejeitavam seus modos de viver, de se comportar e agir na escola, sem apontar saídas para tentar mudar essa realidade.

Essas atitudes discriminatórias e preconceituosas acabavam por incentivar essas crianças a se tornarem mais agressivas e se sentirem desvalorizadas, acreditando realmente serem pessoas sem perspectiva de desenvolvimento e sem um futuro promissor. Como ressalta Cristofoleti (2004), morar na periferia é ser parte da cidade - o que inclui também ser parte de uma parte da cidade, a beirada desprivilegiada. Pertença que inclui, excluindo: entre nós, os moradores da cidade, e eles, os moradores da periferia.

Expressões do tipo: “- Sai daqui seu moleque, tu já pegou teu prato" - isso, geralmente acontecia quando uma criança tentava repetir o seu lanche. "- Vocês são parece bicho do mato" - bradava outra, ante a agitação vivida pelas crianças na fila. "- Parece que nunca viram comidas???” - esbravejava outra, empurrando, grosseiramente, os pratos sobre as crianças.

\section{As Crianças e suas dificuldades}

Pode-se observar que as crianças da $1^{\text {a }}$ série da Escola "Esperança" apresentavam muitas dificuldades em seu percurso escolar, principalmente no que tange ao processo de leitura e escrita. Embora demonstrando algum interesse em adquirir tais conhecimentos, quando colocadas diante desse saber, desenvolviam atitudes de oposição, de conflito, de desinteresse ao processo de aquisição dos conteúdos ensinados.

Observava-se, assim, que essas crianças desenvolviam atitudes de negação e de pouca colaboração com os processos de aprendizagem; demonstravam atitudes que pareciam mostrar que a escola e seus processos de conhecimentos programáticos - leitura e escrita - apresentavam-se como pouco significativos para elas.

O principal problema percebido é que as crianças tinham enormes obstáculos para desenvolver o processo de leitura e escrita. A professora, enfrentando grandes dificuldades diante de uma turma profundamente heterogênea, parecia - em nosso olhar inicial na sua sala de aula - 
desconhecer as dificuldades das crianças nesse aprendizado e se referia a elas, em alguns conflitantes e estressantes momentos, como "burras", "incapazes".

\section{A Professora e sua Prática: O olhar dos pesquisadores}

Aos poucos, fomos tomando conhecimento de como professora e alunos viviam e compartilhavam as práticas de leitura e escrita em sala de aula, buscando evidenciar a questão da mediação afetiva como constitutiva do processo de produção das relações de ensino-aprendizagem, isto é, das relações professsor-aluno-conhecimento.

A dimensão afetiva deveria ser tomada como primordial para o sucesso da leitura e da escrita, este era o nosso entendimento. Na sala de aula, parecia não haver uma relação afetiva positiva, pois a professora desempenhava seu papel de apenas repassar conteúdos no quadro; os alunos, de copiar, em um processo mecânico e sem exploração das significações.

Assim, a metodologia utilizada pela professora reduzia-se ao repasse dos conteúdos na lousa, ditado de palavras soltas, histórias lidas sem comentários significativos, alguns jogos que pareciam ser utilizados como forma de matar tempo e fazer com que as crianças se comportassem bem por alguns breves e fugazes momentos. Por seu turno, algumas crianças tentavam realizar essas atividades sem nenhuma orientação adequada, enquanto outras se encarregavam de desestabilizar a rotina com seus gritos, xingamentos, palavras obscenas, murros, tapas e pontapés umas nas outras.

A rotina - que parecia imutável e desprovida de sentidos, ao olhar e percepção das crianças - gerava desinteresses. A afetividade, ali, com os conhecimentos, era marcada, como já apontamos, pela negatividade e pela recusa. As crianças viviam o estranhamento em relação às atividades propostas, e a professora esforçava-se, a seu modo, em trazer as crianças para um jogo contra o qual muitas delas insurgiam-se com seus dizeres, com suas atitudes e comportamentos.

Ao final de um dos nossos primeiros encontros com a sala de aula, seus alunos e suas dificuldades, a professora, emocionalmente afetada pelas condições em que tentava realizar o seu trabalho, faz-nos um longo e contundente relato de suas percepções sobre essas crianças: 
A turma possui mais de trinta alunos de origem humilde, faixa etária entre sete e quatorze anos, aproximadamente. Ela surgiu a partir de uma seleção de alunos considerados 'perigosos', 'péssimos', alunos que, na avaliação da direção da Escola, não tinham jeito e só iam pra escola pra atrapalhar; eram considerados como 'os incapazes'. Além disso, eram bi, tri e poli-repetentes. No primeiro dia de aula, quando fui me apresentar na escola e na turma, um funcionário me disse: 'Porém, professora! Nós vamos fazer um abaixo-assinado e pedir para o pessoal da prefeitura pagar dois salários para a senhora, porque essa turma é a peneira da peneira'. Em seguida, começou a me apontar, na frente de todos, os alunos 'perigosos' que faziam isso ou aquilo, tipos de vícios que tinham e as atitudes que apresentam. Fiquei calada, sem ação. Ensinar para essa clientela, que muitos consideram condenados ao fracasso, carentes de carinho e conhecimentos, me assustou, mas encarei como um grande desafio. O impacto foi muito grande nos primeiros dias de aula, pois os alunos não têm uma relação muito boa, são crianças com comportamentos de adultos, em que a violência é um dos fatores predominantes na turma, assim como a dificuldade imensa na leitura e na escrita. As agressões são constantes (tanto física como verbal). E isso dificulta o processo de aprendizagem, me colocando em estado de desespero.

\section{0 que fazer? Docência, arte e magia}

Procuramos, diante da situação, promover alternativas diferentes e diversificadas de relação das crianças com a leitura e com a escrita em sala de aula. Desenvolvemos atividades coletivas que viessem permitir a troca de experiência e saberes e possibilitar a interação entre as crianças que vivem em uma realidade de violência, muitas vezes representada em suas brincadeiras em sala de aula, as quais envolvem polícia, brigas de gang etc.

Em colaboração com a professora, instauramos ações didáticopedagógicas, de forma a vivermos a condição da docência, e as criançasadolescentes, a condição de aprendiz como arte e magia, experiência e sabedoria, como nos inspira Benjamin (1994).

Mesmo observando, assim como a professora, que muitas crianças não conseguiam se relacionar de outra forma a não ser por meio de 
agressões verbais e não verbais, a princípio, não tomamos o caminho da repressão ou da condenação. Aos poucos, fomos aprendendo a conviver com elas, intensificando mecanismos pedagógicos e didáticos mediados pelos conhecimentos, para reverter aqueles comportamentos negativos e prejudiciais ao aprendizado.

Assim, em momento algum discriminamos seus gestos e atitudes, pois sabíamos que tudo fazia parte do seu cotidiano, mas que precisava ser mudado, porque aquelas crianças, embrutecidas em condições sociais adversas, careciam de atenção, conhecimento, cultura e carinho para apreenderem e aprenderem os modos humanos de ser, comportar-se, agir e sentir, pois, segundo Vigotski: "As formas como pensamos, nos comportamos, sentimos - a nossa vida cognitiva e afetiva - são socialmente constituídas" (2000a, p. 80).

\section{Resultados Indiciários}

Era uma turma de crianças (algumas pré-adolescentes já) bi, tri e poli-repetentes, que não conseguiam se apropriar da leitura nem da escrita, conhecimentos estes ali trabalhados. Numa mistura de revolta e desinteresse, faziam tudo para chamar a atenção, utilizando-se dos piores artifícios de relacionamento, como brigas, palavrões e ofensas. Parecia que não havia respeito entres colegas e nem pela professora que, mesmo exausta e desestimulada, tentava fazer alguma coisa para mudar aquela realidade.

Constatamos, conforme já anunciado, que as atitudes afetivas, como o descaso, a recusa, o desinteresse pelo conhecimento, eram as marcas dominantes na sala de aula. A única certeza que tínhamos era de que algo precisava ser feito, e com urgência, para que, juntos com a professora, tentássemos outros caminhos de mudança e esperanças, sempre possíveis diante de nossas condições sociais de produção.

A partir de então, começamos juntos, pesquisadores e a professora da turma, a planejar atividades a serem desenvolvidas. Buscamos diferentes formas de trabalhar o conhecimento (leitura e escrita), fugindo da lousa e do giz, sem, contudo, abandoná-la. Procuramos diversificar, a cada dia algo novo, tendo como objetivo chamar a atenção dessas crianças para o 
conhecimento de forma dinâmica, colocando-as sempre como sujeitos da ação, mediados pela professora e por nós, pesquisadores.

Aos poucos, as crianças foram mudando suas atitudes, seus comportamentos. Começaram a dar mais atenção às atividades realizadas em sala de aula, colaboravam com a professora e com os pesquisadores, ajudavam a arrumar a sala, a guardar os materiais utilizados na aula, já conseguiam compartilhar os materiais com os colegas.

A professora, em seus dizeres, relata-nos um episódio no qual se pode perceber os indícios dessas mudanças, quando a indagamos sobre suas percepções em relação ao que estamos fazendo:

Um episódio surpreendente foi o de um aluno muito peralta, que não tinha interesse pelo estudo, mas após algum tempo do início do nosso trabalho, ele chegou a ponto de pular o muro várias vezes só para arrumar as carteiras em círculos antes de começar as aulas. Ele ia à copa, pegava uma vassoura e varria a sala toda, quando entrávamos, ele pedia permissão para buscar nossas lixeiras que guardávamos na secretaria juntamente com minha caixa de giz. Por conta própria se tornou meu assistente e mudou totalmente de comportamento.

$\mathrm{Na}$ medida em que as ações foram acontecendo, fomos igualmente observando graduais mudanças na configuração afetiva da sala de aula, provocando alterações e novas relações com o conhecimento em circulação e elaboração. Não se recorria à pressão para que realizassem as atividades, já faziam por vontade própria; passaram a participar ativamente das aulas, a perguntar e expressar suas opiniões. Observamos que as atividades estavam conseguindo despertá-los para o conhecimento.

A professora, mostrando-se satisfeita com o trabalho em parceria e com os resultados que colhíamos, entregou-nos, por escrito, os seguintes dizeres:

Aqueles olhares me surpreendiam a cada dia, a cada aula. Neles, o esforço para mostrar que são capazes. O sorriso. Os abraços. Faziam-me feliz em poder ver o crescimento, o avanço daquelas crianças. E para os pesquisadores acho que não está sendo diferente, pois eles também contribuem em muito para o sucesso das mesmas. Nossas aulas, planejadas 
coletivamente aos finais de semana, assim como a confecção de material didático, vêm apresentando bons resultados. $\mathrm{O}$ trabalho em parceria vem me mostrando um bom caminho de aprendizagem e de refletir e rever minha prática.

Em sua espontânea manifestação discursiva, a professora nos fez ver o importante papel da mediação intersubjetiva para a formação continuada do professor. Vygotsky defende a tese de que é nas relações intersubjetivas, nas relações sociais, mediadas por experiências e conhecimentos, que vamos forjando nossa subjetividade, bem como os elementos norteadores de nossas formas de agir e sentir.

A reflexão, para Vygotsky (1998), ocorre no processo intersubjetivo, na relação eu-outro-outros. Isolados em suas salas de aulas, sem interlocutores com quem compartilhar seus medos, suas angústias, os professores mofam em uma prática mecânica e repetitiva. A formação, assim, não é um processo solitário; formamo-nos nas relações sociais, na interação interdiscursiva. A arte e a magia, que se insinuam em nossos saberes e fazeres, atualizam-se, constituem-se e se transformam no teatro das relações sociais. E naquela sala de aula parecia não se fazer diferente, pois a professor foi se apercebendo disso.

Benjamin (2002) defende, assim como Vygotsky, a ideia de que o processo de formação somente é possível nas relações entre os indivíduos que compartilham entre si saberes e experiências. Para este pensador, a formação humana, na modernidade, vem sofrendo um monstruoso processo de empobrecimento, diante do avanço da técnica e da informação, as quais massificam os sujeitos, retirando-lhes a possibilidade de ter acesso aos saberes e às experiências mais significativos.

Para Benjamin, informação não deve ser confundida com saber. O saber e a experiência nos transformam, a informação passa por nós sem nos afetar, sem nos modificar; tomamos conhecimento dela como mais um objeto produzido pela massificação tecnológica. Há, assim, uma hiperinflação de informação, por um lado, e, por outro, um hiperempobrecimento da formação humana. Contraditoriamente, segundo Benjamin, quanto mais informação é disponibilizada, mais nos enredamos num processo de barbárie de uma formação apequenada, necessária unicamente para adaptar-nos às demandas da ordem industrial e técnico-científica.

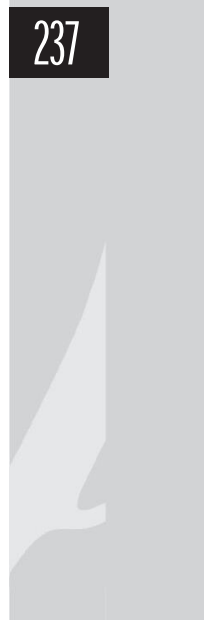


Formando-se na relação intersubjetiva, no intercambiamento de experiências e saberes, a professora lança um olhar reflexivo sobre o seu fazer e sobre os seus alunos e vai percebendo, então, como o conhecimento e a aprendizagem passaram a mobilizar as crianças: - "Não faltaram mais às aulas, quando chegavam perguntavam o que iríamos trabalhar", dizia a professora nos dias de nossos encontros. Era o conhecimento afetando as crianças de forma criativa, prazerosa, significativa, mobilizandoas à apropriação das necessárias experiências de aprendizagem para constituírem-se como sujeitos.

Criativa porque lhes possibilitava a interação, a enunciação de seus dizeres, mesmo em seus fragmentos; dava-lhes a oportunidade de agir de forma dinâmica e diversificada sobre os conhecimentos propostos, sempre mediados pela professora e pelos pesquisadores.

Prazerosa porque se sentiam aprendendo; descobriam para que servem a leitura e a escrita, assim como a sua função social; prazerosa porque, após muito esforço e atenção, colhiam os frutos desse esforço, materializados na leitura ou escritura de um pequeno texto. A emoção de prazer, assim, funcionando como o elemento mediador da aprendizagem, alimentando o desenvolvimento cognitivo.

A emoção de prazer, ressaltamos, deve ser vista com muito cuidado nas relações de ensino, pois no processo de aprendizagem as crianças precisam desenvolver a atenção, a percepção, a auto-regulação de atitudes, ou seja, precisam apropriar-se de comportamentos socialmente aceitos e valorizados pelo grupo social.

O desenvolvimento cognitivo exige, assim, muito esforço da criança para a apropriação de determinadas competências e habilidades. As emoções alimentam o desenvolvimento cognitivo, que, por sua vez, regula e amplia a dimensão emocional. Desenvolvendo as competências cognitivas, a criança frui a emoção de prazer e alegria, que ao mesmo tempo a impulsionam a novas aprendizagens. Mas o esforço, o trabalho cuidadoso, a atenção concentrada nem sempre podem ser vistas como unicamente prazerosas. Estudar, aprender, por conseguinte, exige rigorosidade, comportamento metódico, renúncias, etc.. E as crianças não estão excluídas desses processos.

Vygotsky pressupõe uma compreensão da vida psíquica entrelaçada entre aspectos afetivos e intelectuais, em sua historicidade, em seu 
processo dialético de transformação, sendo regulada, desenvolvida e transformada pelos sentidos e pelas significações de que o sujeito se apropria na sua inserção social e cultural. Para Vigotski, o humano não está no que ele chama de funções psicológicas inferiores, que seriam aquelas de base orgânica, naturais, mas nas funções psicológicas superiores, que são constituídas e transformadas pela cultura e pelo processo histórico (1997, 2000a, 2000b, 2000c). Todas as funções superiores são constituídas socialmente, pela significação, que é apropriada pelos sujeitos no interior das relações sociais. Assim, "sua composição [daquelas funções], gênese, função - em uma palavra, sua natureza - são sociais" (VIGOTSKI, 2000c, p. 27).

Para Vygotsky, o que é fundamental como característica humana é justamente a capacidade de significar, nomear as ações e os sentimentos, a capacidade de projetar e planejar, antecipando o que o sujeito vai viver; de ter controle sobre si mesmo, sendo capaz de antecipar ou retardar o prazer. É aí que se delineia o elemento fundamental para a compreensão da vida psíquica do ser humano e igualmente das emoções, como parte daquela, em seu processo de transformação.

Essa característica humana também se apresenta igualmente fundamental para compreendermos os processos de aprendizagem. Podese pressupor que a criança se esforça para aprender, enfrenta exigências, rotinas rigorosas para apropriar-se das significações socialmente necessárias para a sua vida, quando consegue projetar as emoções de prazer decorrente desse esforço.

Por um lado, o ato de aprender e a compreensão desencadeiam as emoções de prazer, que realimentam novos investimentos cognitivos do sujeito no campo da aprendizagem. Por outro, o não-aprender, o nãocompreender, desencadeiam nas crianças aquelas emoções de recusa e de estranhamento às práticas pedagógicas e aos conhecimentos que lhes são disponibilizados na sala de aula. Nesse momento, percebe-se o enlace afetividade e conhecimento, mobilizando ou não as crianças ao aprendizado. $\mathrm{O}$ acesso ao conhecimento e às significações vai alterando o processo de intersubjetividade vivido pelas crianças. E elas vão se autoregulando, porque estão se apropriando de outros modos e práticas de agir, pensar e sentir, ou seja, elas estão constituindo seus "eus", sua vida psíquica nas relações de conhecimentos, que são relações sociais e culturais. 
A metodologia em ação comportava inúmeras atividades, como: leitura e produção de diferentes gêneros textuais, jogos, brincadeiras, músicas e lendas regionais, mitos e contos de fada, teatro, dança, pintura, historinhas, filmes infantis e adultos, ditados com palavras móveis, atividades orais etc. Em todos os eventos, sempre e necessariamente, a leitura e a escritura estavam presentes, sendo estimuladas e exploradas. A professora e seus dizeres:

\begin{abstract}
Através do cantinho da leitura, oportunizamos às criançasadolescentes o contato com diferentes tipos de textos. A sala de aula tornou-se um ambiente letrado, com muitos cartazes para manter as crianças em contato com as letras, com o mundo da leitura e escrita. Aprendi a transformar a minha sala de aula em um ambiente alfabetizador. Minhas colegas me perguntam o que eu fiz para melhorar a aprendizagem de meus alunos e eu respondo: transformei minha sala em um ambiente alfabetizador e elas perguntam: o que é um ambiente alfabetizador. Aí eu explico para elas.
\end{abstract}

Deve-se destacar, em relação à metodologia aplicada, que, para Vigotski, o importante é colocar a criança em contato e em interação com toda a riqueza simbólica disponível, com os produtos culturais e semióticos os mais diversos possíveis. Em relação à brincadeira, Vigotski (1998) acredita que esta desempenha um importante papel no desenvolvimento das funções mentais e do funcionamento psicológico da criança.

A brincadeira é a realização do enlace afetividade e cognição. $\mathrm{Na}$ brincadeira, segundo Vigotski, as crianças vão se experimentando nos modos humanos de ação, pensamento e sentimento. Nesse jogo, o sujeito vai tecendo a sua biografia no indissociável enlace cognição, afeto e emoções. O brincar apresenta-se como uma forma de desenvolvimento do ser humano, desde que lhe proporcione satisfação diante do que está realizando. Assim, a criança vai aprendendo e se constituindo de forma dinâmica na relação com o outro, no processo de intersubjetividade, mediada pelos conhecimentos, significações, linguagens etc.

A professora em seus dizeres: 
Tivemos oportunidade de ouvir histórias e contarmos as nossas histórias, além de cantar, dançar, pular, saltar, brincar, observar, ler e escrever. De aprender, mediados pela brincadeira e com os conteúdos programáticos, de formas diversificadas, uma rotina de trabalho variada, incentivando-os todo o tempo. Trabalhamos com a produção de pequenos textos, onde líamos alguns textos ou historinhas e pedíamos para que representassem através de escrita ou desenhos o que haviam entendido. Dávamos a eles a oportunidade de criar livremente seus desenhos e seus textos. O impressionante é que em cada desenho estavam refletidos traços de sua realidade, pessoas brigando, crianças brincando na rua, casas mal feitas, que pareciam representar suas casas, outras bonitas que gostariam de ter, outros rabiscavam e liam o que escreviam, tudo parecia refletir seu espaço sociocultural, seu imaginário, sonhos e esperanças. As crianças, assim, interpretavam e construíam seus textos baseados nas suas experiências pessoais: suas cargas afetivas e seus conhecimentos prévios eram agregados às informações lidas e produzidas. Através das atividades propostas, as crianças se identificavam com as situações apresentadas e utilizavam essas experiências para reescrever sua própria historia de vida, refletir sobre a sua condição como participantes das relações sociais e da cultura.

A leitura e a escritura não são processos de mão-única, pelo contrário, trazem para o leitor um mundo que se articula com as suas vivências. $O$ leitor, assim, apropria-se dos textos a partir de seus referenciais, de suas experiências, dos conhecimentos prévios. Reelaborando o conteúdo de suas leituras; o leitor produz conhecimento.

As crianças, produzindo seus textos, produziam conhecimento. Apropriavam-se e transformavam as significações recebidas e eram transformadas por elas. Interagindo e ampliando a dimensão sígnica do material simbólico recebido, as crianças internalizam os modos socioculturais de pensar e agir, regulavam seu funcionamento psíquico, suas formas de subjetivação da vida e do mundo.

A utilização do vídeo em sala de aula foi outro fator que ajudou muito na mudança de atitude das crianças em relação à construção do conhecimento nesse ambiente, pois era algo que chamava a atenção, instaurava momentos ricos em interlocução: elas discordavam, criticavam 
e davam suas opiniões a respeito do que viam e ouviam. Na interlocução, aprendiam as regras necessárias às relações sociais, pois não tinham apenas que falar, mas também saber ouvir, esperar e respeitar o direito do colega em pronunciar-se.

O vídeo, além da linguagem visual, também recorre à escrita, pois seus textos, legendas, frases ajudam as crianças a interagir diretamente com o conhecimento em produção e elaboração. $\mathrm{O}$ vídeo, dessa forma, traz as linguagens oral, musical e escrita, interligadas, possibilitando sua comunicação e permitindo o acesso da criança às várias modalidades de linguagem. No início, os filmes infantis foram de imediato rejeitados, em sala de aula, pelas crianças-adolescentes, que diziam: "Esse filme é de criança, não vou assistir, eu não sou criança"; "Era pra gente assistir filme de ação", e o outro respondia, "Pior, é pouco bacana, isso daí é só bobagem".

Sentimos um pouco de dúvida em relação aos desejos que nutriam essas crianças-adolescentes em assistir filmes que envolviam diversas formas de violência, morte, prostituição, drogas, mas depois, em diálogo com a professora, concluímos ser viável atender a tais pedidos.

A partir de então, começamos a mostrar em sala de aula filmes que tinham ligações com aquela realidade de violência vivida por eles. Não para dizer depois que não devem fazer o que o filme mostra. Mas para dar a eles a oportunidade de opinar a respeito do que viam, e isso acontecia de forma muito significativa, alimentando, ampliando e enriquecendo as interlocuções entre as crianças, a professora e os pesquisadores.

Nessas interlocuções, relatavam histórias horríveis vivenciadas por elas. Afirmavam, contudo, não concordar com aqueles atos de agressão para com os seres humanos.

Agimos, assim, de forma a valorizar os conhecimentos trazidos pelos educandos, ligando sua realidade aos conceitos científicos da escola. Os conceitos espontâneos, confrontando-se com os conceitos científicos, tornam-se, na maioria das vezes, um dos fatores decisivos para o não desenvolvimento das funções mentais, para a evasão e o fracasso escolar. Os educadores, não se dando conta da importância da valorização dos conhecimentos trazidos pelos indivíduos para o contexto sistemático, acabam impondo um conhecimento que nada tem a ver com a realidade de cada um. São conhecimentos trabalhados de forma mecânica, vistos 
pelas crianças como algo sem importância, sem significado para sua vida, afastando-as cada vez mais do processo de aquisição da leitura e da escrita.

\section{Conclusão}

O desenvolvimento da Pesquisa na Escola "Esperança" foi de uma importância inquestionável, pois ajudou aquelas crianças a se apropriarem de outros modos de comportamento: já conseguiam manter relações mais amigáveis com os colegas, educadores e com os outros funcionários da instituição; não mais destroem cartazes e murais expostos em sala de aula, muito pelo contrário ficavam irritados quando chegavam à sala e viam seus trabalhos destruídos ou levados por alunos de outras séries; ficavam tão chateados, e vinham reclamar à professora e aos pesquisadores.

Conseguimos despertar neles o gosto pela leitura e pela escrita, levando-os a serem vistos pela escola não mais como os "piores", os "animais", os "marginais" e sim como crianças iguais a quaisquer outras que sentem, sofrem, têm valores, cultura e que necessitam, antes de tudo, ser compreendidas, pois o carinho, o afeto são também fatores determinantes no processo de ensino-aprendizagem.

$\mathrm{O}$ aprender e a apropriar-se dos conhecimentos mudou essas crianças em sua auto-estima e as motivou ao investimento em novas aprendizagens.

Pela apropriação dos conhecimentos, modificaram-se a si mesmas, modificaram a imagem que tinham de si mesmas, assim como a imagem que deles faziam os profissionais da escola. Ou seja, ressignificaram as relações sociais ali estabelecidas e vividas. Adquiriram formas adequadas de se comportar em sala de aula, além de dar importância e valor aos conhecimentos ali trabalhados. A esse respeito, vejamos a professora e seus dizeres: "Mas um dos pontos positivos foi que os alunos só faltavam quando estavam doentes ou viajando para algum interior do município, mesmo assim os pais justificavam suas faltas".

A afetividade é um requisito fundamental no desenvolvimento do ser humano, pois, por meio dela, podemos perceber a evolução dos indivíduos e sua relação com o conhecimento. Compreende-se que a afetividade desenvolvida em sala de aula não são apenas aquelas relações de carinho, atenção, paciência, ajuda e colaboração que os educadores 
deveriam dedicar a seus alunos. Mas envolve a recusa, o descaso, o desinteresse dos alunos pelo conhecimento, que também são formas de mostrar o quanto se está sendo afetado, e muito, pelas relações sociais vividas (FALABELO, 2005).

As ações didáticas, pedagógicas e culturais despertaram a curiosidade daquela $1^{\mathrm{a}}$ série, pois todos queriam saber, assim que eles chegavam à escola, o que seria realizado a cada novo dia. Corriam para nos receber e iam logo perguntando:

- "O que nós vamos estudar hoje?" - "Nós vamos assistir DVD?" "Qual é o filme que nós vamos ver hoje?" - "Nós vamos escrever?" - "A gente vai desenhar, colar, pintar, brincar?" - "O que a gente vai ler hoje? - "Vai ter joguinho?" - "O que nós vamos fazer?”.

Essas eram as perguntas, cheias de curiosidades e expectativas, que passamos a ouvir todos os dias daquelas crianças que, no início, pareciam não dar valor ao conhecimento que lhes eram ensinados. Sobre as mudanças de comportamento observadas, em seu depoimento a professora constata:

Às vezes, eles convidavam colegas de outras salas para assistir às aulas conosco, ou então, quando algum professor faltava, a maioria dos alunos pedia para assistir aula na nossa sala, $e$ ainda tinha alunos que levavam os irmãos menores, que a mãe mandava, para assistir à aula, e nós não dizíamos não.

A partir do momento em que começamos a desenvolver as atividades com o objetivo de colocar as crianças como sujeitos na construção do conhecimento, passamos a perceber o entusiasmo da professora em inovar suas metodologias e contribuir significativamente nos momentos de planejamento, sugerindo maneiras diferenciadas de trabalhar os conteúdos programáticos e motivar seus alunos.

A professora sempre desejara ajudar aquelas crianças - nos confessou certo dia -, mas sozinha, sem o apoio da escola, na solidão de seu fazer, sentia-se desestimulada e desencorajada a cada dia e ameaçada pelos seus próprios alunos. Em colaboração com os pesquisadores, mudou a sua rotina, as condições de aprendizagem de seus alunos e alterou o destino de muitas daquelas crianças, que começaram a aprender a ler e a escrever, a se desenvolver, modificando suas atitudes e seus comportamentos. 
Hoje ela se confessa vitoriosa por superar seus limites e mostrar para todos que não se deve dar por perdida uma causa antes de lutar, principalmente quando se trata de crianças e de seu desenvolvimento como ser social, e, ainda, mostrar que com a ajuda do outro se vai longe, conforme ilustra a professora:

Ao final do ano letivo o progresso dessas crianças foi grande. Todos saíram sabendo escrever o nome, conhecendo o alfabeto e lendo frases e pequenos textos. Aquelas crianças, que estavam em fase de coordenação motora, evoluíram bastante, mas não estavam em condições de cursar a $2^{a}$ série e permaneceram na primeira para continuar seu processo de aprendizagem. A cada dia uma novidade prendia a atenção dos alunos. Acredito que essa experiência foi muito válida para minha formação continuada, pois adquiri novas experiências, que são repassadas aos colegas de profissão, porque foi uma experiência inesquecível e que deu certo, e que, por esse motivo, deveria continuar e fazer a diferença na vida de outras pessoas, de outras crianças.

A nós, pesquisadores, igualmente, a inserção na sala de aula foi de suma importância, pois nos possibilitou vivenciar a realidade de uma sala de aula e a dramática situação de crianças pobres em pobres escolas da periferia; colocar em prática os conhecimentos teórico-metodológicos; conhecer a importância de estarmos cientes de que uma turma de alunos nunca é homogênea e sim heterogênea e que nós (pesquisadores), como educadores, precisamos trabalhar com as diferenças e ter em mente que as crianças, ao entrarem em uma sala de aula, trazem consigo uma história de vida que necessita ser levada em consideração no momento de se ensinar os conhecimentos escolares. Só assim iremos ajudá-los em sua formação.

O conhecimento, que antes parecia ser visto pelas crianças como algo sem importância, sem sentido algum para elas, passou a tomar outra dimensão, pois elas começaram a demonstrar uma afetividade de aceitação pelo conhecimento, deixando de lado a recusa, o descaso, que durante algum tempo dominavam a turma.

As crianças, em gestos, atitudes, comportamentos verbais e nãoverbais, em suas fisionomias, pareciam insinuar que o conhecimento lhes proporcionava momentos de felicidade e sentimento de valorização. 
Sentiam-se importantes como participantes daquela turma. Passaram a se interessar mais pela leitura e pela escrita. Os indícios de mudança do comportamento das crianças eram visíveis.

Verificamos que o conhecimento mobiliza as crianças, fazendoas ver os laços de afetividade que vão sendo produzidos nas relações de aprendizagem. Ou seja, o afeto mostra-se, mesmo, nas relações com o conhecimento. É o conhecimento que mobiliza o sujeito; é o conhecimento que sustenta a relação de ensino; é o conhecimento, portanto, que sustenta as relações sociais que se desenvolve na sala de aula, envolvendo professora-aluno e alunos-alunos.

Vigotski (2000b) nos adverte para que não ignoremos as necessidades dos sujeitos, assim como os incentivos que são eficazes para colocá-los em ação, pois, se os ignorarmos, nunca seremos capazes de entender seu avanço de um estágio do desenvolvimento para outro, porque todo avanço está conectado a uma mudança acentuada nas motivações, tendências e incentivos.

As formas como apresentamos os conhecimentos, ou seja, as condições concretas de produção das relações de ensino afetam os impulsos afetivos das crianças em relação ao aprendizado, podendo tornálas mais ou menos receptivas a ele. Nesse sentido, o outro desempenha um papel fundamental na internalização dos processos sociais e culturais de comportamento, tanto no aspecto cognitivo quanto no aspecto afetivo, instaurando, mediando, regulando as relações do sujeito com sua aprendizagem e consigo mesmo. A mudança de atitude da criança, em seu processo de formação, passa pela relação com o conhecimento e pela mediação do outro, na medida em que ambos afetam as relações interfuncionais do psiquismo.

$\mathrm{O}$ processo de internalização dos objetos, práticas e significados culturais, ao longo do desenvolvimento do psiquismo, modifica as formas

dor de

O processo de alfabetização vivenciado pelas crianças, possibilitando-lhes a apropriação do objeto cultural escrita e a habilidade leitora, não afeta apenas o desenvolvimento de sua cognição, propiciando-lhes outros modos de relação cultural. Ela re-significa sua condição social de alunos, na medida em que confere sentido a sua permanência na sala e sustenta seus investimentos na aprendizagem. 
O modo como as crianças sentem e vivem sua condição de alunos, foi mediado pela professora, pelos pesquisadores-professores, pelos colegas, mas, por sua vez, mediatiza esses seus outros reconfigurando suas disposições afetivas em relação a elas (crianças), pois "é por intermédio do outro - de suas ações, de suas palavras, da maneira como se dirige ao eu e interage com ele - que o eu vai tomando forma no mundo" (OLIVEIRA, 2001, p. 5).

As crianças, apropriando-se dos conhecimentos, reorganizando e regulando seus comportamentos ao que é social e culturalmente esperado, deixaram de ser alvos dos comentários depreciativos de muitos membros da escola e passaram a viver a escola em sua especificidade de lugar de conhecimento, de relações sociais e culturais, de compartilhamentos, enquanto atos que se insinuam como experiência, arte e magia.

\section{REFERÊNCIAS}

BAKHTIN, M. Marxismo e filosofia da linguagem. São Paulo: Hucitec, 1997.

FALABELO, R. N. O. A Indissociável inter-relação afetividade e cognição nos processos de leitura e escrita na educação de jovens e adultos. Tese de Doutorado. Piracicaba: Faculdade de Educação/ Universidade Metodista de Piracicaba, 2005.

FONTANA, R. A. C. Mediação pedagógica na sala de aula. Campinas: Autores Associados, 2000.

FONTANA, R. A. C. Nas relações de ensino o aprendizado da escuta. In: ALMEIDA e SILVA (Org). Textos, palestras e sessões temáticas. III Encontro de Linguagens, leituras e ensino de ciências. Campinas: FE/ UNICAMP, 2000.

FONTANA, R.; CRUZ, N. Psicologia e trabalho pedagógico. São Paulo: Atual, 1997.

GÓES, M. C. R. de. A construção de conhecimentos e o conceito de zona de desenvolvimento proximal. In: Encontro sobre Teoria e Pesquisa em Ensino de Ciências: linguagem, cultura e cognição - reflexões para o ensino de ciências 05-07/03/1997, Belo Horizonte. Anais... Belo Horizonte, 1997. 
GÓES, M. C. R. de. A Natureza social do desenvolvimento psicológico. Cadernos CEDES, n. 24, 1991.

GÓES, M. C. R. de. As relações intersubjetivas na construção de conhecimentos. In: GÓES, M. C. R. de; . (Org). A significação nos espaços educacionais: interação social e subjetivação. Campinas: Papirus, 1997.

OLIVEIRA, M. K. de. Vygotsky: aprendizado e desenvolvimento: um processo sócio-histórico. São Paulo: Scipione, 1997.

PADILHA, A. M. L. Possibilidades de histórias ao contrário ou como desencaminhar o aluno da classe especial. São Paulo: Plexus, 1997.

SÈVE, L. A personalidade em gestão. In: SILVEIRA, P.; DORAY, B. (Org.). Elementos para uma teoria marxista da subjetividade. São Paulo: Vértice/Ed. Revista dos Tribunais, 1989.

SMOLKA, A. L. B. Esboço de uma perspectiva teórico-metodológica no estudo de processos de construção de conhecimento. In: GÓES, M. C. R. de; __ (Org.). A significação nos espaços educacionais: interação social e subjetivação. Campinas: Papirus, 1997.

SMOLKA, Ana Luiza Bustamante. A criança na fase inicial da escrita: a alfabetização como processo discursivo. São Paulo: Cortez; Campinas, SP: Editora da UNICAMP, 1999.

VYGOTSKY, L. S. A Construção do pensamento e da linguagem. São Paulo: M. Fontes, 2001.

VIGOTSKI, L. S. A Formação social da mente. São Paulo: M. Fontes, 1998.

VYGOTSKY, L. S. Aprendizagem e desenvolvimento intelectual na idade escolar. In: ; LURIA, A. R.; LEONTIEV, A. N. Linguagem, desenvolvimento e aprendizagem. Paulo: Ícone: EDUSP, 1988.

VYGOTSKY, L. S. Pensamento e linguagem. São Paulo: M. Fontes, 1998.

VYGOTSKY, L. S. Teoria e método em psicologia. São Paulo: M. Fontes, 1998. 